LINGUAGEM MÉDICA

\title{
MORBIDADE, MORBILIDADE
}

Joffre M. de Rezende ${ }^{1}$

Os dois termos acima têm sido utilizados com o mesmo significado e com duas acepções: "1. Capacidade de produzir doença num indivíduo ou num grupo de indivíduos. 2. Relação entre o número de pessoas sãs e o de doentes, ou de doenças, num dado tempo e quanto à determinada doença." (2). Nesta segunda acepção constitui um índice epidemiológico, o indice de morbidade, que se desdobra nos coeficientes de incidência e de prevalência (4).

Estamos diante de duas formas paralelas para designar o mesmo fato. Qual seria a forma preferível?

Ambas provêm da palavra latina morbus, $\boldsymbol{i}$, que significa tanto doença física, enfermidade, como doença do espírito, paixão (5). De morbus + diminutivo illus formou-se morbillus, $\boldsymbol{i}$, nome primitivo da varíola que passou a designar sarampo. De morbilli deriva morbiliforme em português, que quer dizer com o aspecto de sarampo, semelhante ao sarampo. Dentre os cognatos de morbus em latim está o adjetivo morbidus, $\boldsymbol{a}, \boldsymbol{u m}$, que corresponde a mórbido em português.

Parece óbvio que o vocábulo formado em português com a raiz morbi- e o sufixo -dade só poderia ser morbidade. A introdução da sílaba li faz lembrar morbilli, relativo ao sarampo. Entretanto, uma coisa é a lógica e outra os fatos da língua. Talvez a forma com o acréscimo da sílaba li, morbilidade, tenha surgido por analogia com mortalidade, uma vez que ambos os termos andam sempre juntos. Ou tratar-se-ia de um recurso eufônico?

Em italiano, usa-se morbilità e, em espanhol, morbilidad ou morbididad. Em inglês, encontramos morbidity e morbility, este último termo pouco usado. Do mesmo modo, em alemão temos morbididät e morbilität. Em francês, prevaleceu morbidité. Em português, devemos optar entre morbidade e morbilidade.

1 Professor Emérito da Universidade Federal de Goiás.

Endereço para correspondência: E-mail: jmrezende@cultura.com.br http://usuarios.cultura.com.br/jmrezende

Recebido para publicação em: 24/5/2012. 
Conforme ressaltou Plácido Barbosa, "morbidade é de formação mais conforme à estrutura do étimo morbidus, no qual não existe $l$ "'(1).

Os nossos léxicos titubeiam entre uma e outra forma. Averbam somente morbidade Pedro Pinto (1962), Antenor Nascentes (1966) e Aurélio Ferreira (2004); abonam apenas morbilidade Silveira Bueno (1963) e Aulete-Garcia, (1980); aceitam as duas formas Cândido de Figueiredo (1949), Houaiss (2001) e o Vocabulário Ortográfico da Academia Brasileira de Letras (2009). Rey, em seu Dicionário de termos técnicos de medicina e saúde (1999), considera sinônimos os dois termos e registra morbilidade com remissão para morbidade, o que pressupõe preferência por esta forma.

O Glossário de Epidemiologia, publicado como suplemento dos Arquivos da Faculdade de Higiene e Saúde Pública da Universidade de São Paulo, registra apenas morbidade (5). Por sua vez, os Descritores em Ciências da Saúde da BIREME optaram por morbidity em inglês, morbilidad em espanhol e morbidade em português, que me parece a forma que deve prevalecer por ser a forma corrente na literatura médica. Em um total de 427 artigos escritos em português indexados na BIREME, tendo no título um dos termos de que nos ocupamos, somente nove usaram morbilidade.

\section{REFERÊNCIAS}

1. Barbosa P. Dicionário de terminologia médica portuguesa. Rio de Janeiro, Liv. F. Alves, 1917.

2. Ferreira ABH. Novo dicionário da língua portuguesa, Rio de Janeiro, Ed. Nova Fronteira, 1999.

3. Rey L. Dicionário de termos técnicos de medicina e saúde. Rio de Janeiro, Guanabara Koogan SA, 1999.

4. Rouquayrol MZ. Epidemiologia e Saúde. 2.ed., Rio de Janeiro, Medsi, 1986.

5. Saraiva FRS. Novíssimo Dicionario latino-português. Rio de Janeiro, Liv. Garnier, 1993.

6. Schmid AW. Arq Fac Higiene e Saúde Pública Univ São Paulo 10: 1-20, 1956

NOTA: Modificado do livro do autor Linguagem Médica, 4a .ed. Goiânia, Ed. Kelps, 2011. 